\title{
Stem cells supporting other stem cells
}

\section{Judith Leatherman*}

School of Biological Sciences, University of Northern Colorado, Greeley, CO, USA

\section{Edited by:}

Halyna R. Shcherbata, Max Planck

Society, Germany

\section{Reviewed by:}

Abhijit Shukla, Harvard Medical School, USA

Todd Nystul, University of California at San Francisco, USA

\section{*Correspondence:}

Judith Leatherman, School of

Biological Sciences, University of

Northern Colorado, 501 20th Street,

Greeley, CO 80639, USA

e-mail: judith.leatherman@unco.edu
Adult stem cell therapies are increasingly prevalent for the treatment of damaged or diseased tissues, but most of the improvements observed to date are attributed to the ability of stem cells to produce paracrine factors that have a trophic effect on existing tissue cells, improving their functional capacity. It is now clear that this ability to produce trophic factors is a normal and necessary function for some stem cell populations. In vivo adult stem cells are thought to self-renew due to local signals from the microenvironment where they live, the niche. Several niches have now been identified which harbor multiple stem cell populations. In three of these niches - the Drosophila testis, the bulge of the mammalian hair follicle, and the mammalian bone marrow - one type of stem cell has been found to produce factors that contribute to the maintenance of a second stem cell population in the shared niche. In this review, I will examine the architecture of these three niches and discuss the molecular signals involved. Together, these examples establish a new paradigm for stem cell behavior, that stem cells can promote the maintenance of other stem cells.

Keywords: stem cell niche, stem cell therapy, hair follicle stem cell, hematopoietic stem cells, Drosophila stem cells, germline stem cell, self-renewal pathways

\section{INTRODUCTION}

The field of stem cell biology has seen numerous studies over the years touting the benefits of stem cell therapies. Injection of various types of adult stem cells were able to improve conditions such as myocardial infarction, spinal cord injury, and muscle degeneration (McDonald etal., 1999; Orlic et al., 2001; Dezawa etal., 2005). In these early studies, it was originally assumed that the benefits arose from true tissue regeneration due to stem cell differentiation into specific cell types. However, further examination of these improvements revealed that very few stem cell-derived cells were actually incorporated long-term into the tissues of interest. It is now well appreciated that stem cells secrete paracrine factors which have a trophic, cell protective effect on extant tissue cells, and much of the improved tissue functionality in disease models can be attributed to this effect, rather than new cells from the stem cells (Zandonella, 2005; Caplan and Dennis, 2006; Gnecchi et al., 2008; Pelacho and Prosper, 2008; Uccelli et al., 2011).

Does this idea that stem cells secrete a "special juice" have anything to do with the normal functioning of stem cell populations? Recent findings in three different adult stem cell niches - the Drosophila testis, the mammalian hair follicle, and the mammalian bone marrow - provide evidence that it does. Each of these stem cell niches harbor two separate populations of stem cells, and in each example, one stem cell population has been found to provide important molecular signals that keeps the other self-renewing.

\section{THE Drosophila TESTIS NICHE}

In the Drosophila testis, sperm production is maintained over the lifetime of adult flies by continual division of two stem cell populations, the germline stem cells (GSCs) and the cyst stem cells (CySCs). Why two stem cell populations? Just as in mammalian spermatogenesis, the germ cells must be guided through the differentiation process by specialized somatic cells; in mammals these are the Sertoli cells, and in Drosophila they are the cyst cells. Both Sertoli and cyst cells completely engulf germ cells within their cytoplasm, providing important differentiation cues. However, while Sertoli cells are long-lived cells that are re-used by each group of differentiating germ cells, Drosophila cyst cells associate with each packet of differentiating germ cells, do their job of germ cell guidance, and then die. Thus, new cyst cells must also be continually produced by a stem cell population, and sperm production is dependent on both stem cell populations. The two stem cell populations must also coordinate their division rates, since their differentiating progeny associate with each other, with two cyst cells for each differentiating germ cell.

The two stem cell populations share a common niche, intermingling around a group of cells called the hub (Hardy et al., 1979). When either type of stem cell divides, the daughter cell that stays in contact with the hub self-renews, while the daughter that loses contact with the hub will differentiate (Yamashita et al., 2003). As soon as a differentiating germ cell moves away from the hub, it is called a gonialblast, and it is immediately engulfed, or encysted, by two cyst cells. As differentiation commences, the gonialblast undergoes a transit amplification (TA) period, followed by meiosis. The cyst cells, in contrast, immediately withdraw from the cell cycle upon exit from the niche, and simply stretch their cytoplasmic arms to engulf the growing group of differentiating germ cells (Figure 1A).

It was originally thought that the two stem cell populations in this niche self-renewed independently from each other, both in response to the secreted cytokine Upd from the hub, which activates Jak/STAT signaling in the stem cell populations. Ectopic Upd expression caused ectopic accumulation of both stem cell 


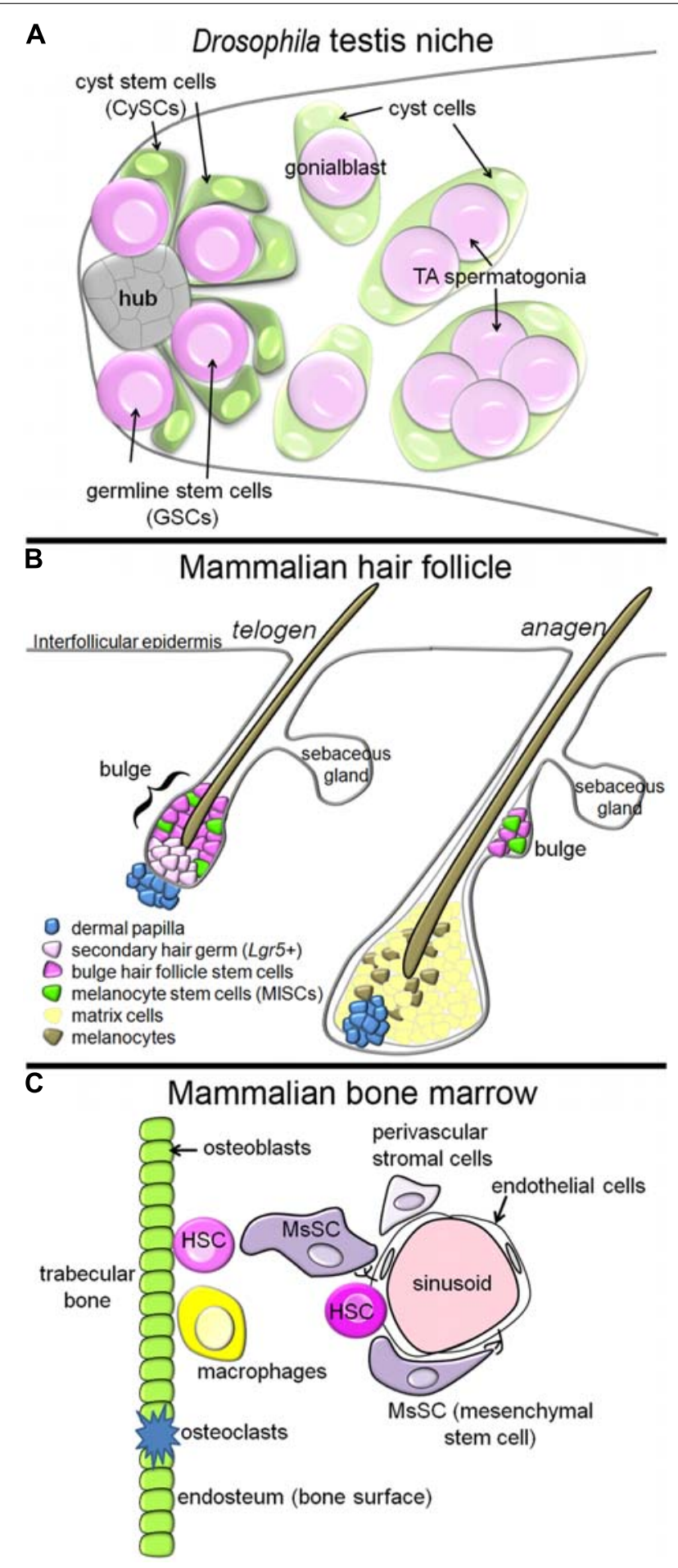

FIGURE 1 |Tissue architecture of three stem cell niches. (A) In the Drosophila testis niche, two stem cell populations, the GSCs and CySCs, intermingle around a cluster of cells called the hub. When the stem cell populations divide, daughters that move away from the hub differentiate, and the differentiating germ cells, which begin to undergo TA, become encysted by the differentiating cyst cells. In this niche, the CySCs produce signals promoting the self-renewal of neighboring GSCs. (B) In the mammalian hair follicle, the bulge and SHG HFSCs reside next to the

(Continued)

\section{FIGURE 1 | Continued}

dermal papilla during telogen, and the MISC intermingle with the HFSCs. During anagen, the HFSCs and MISCs divide to produce matrix cells and melanocytes, respectively, which cluster around the dermal papilla and contribute to growth of the new hair. The HFSCs provide molecular signals a different stages of the hair follicle cycle which regulate the behavior of the MISCs. (C) In the mammalian bone marrow, HSCs have been identified next to sinusoids (blood vessels) and next to the endosteum (osteoblasts). MsSCs, which are innervated by the sympathetic nervous system, cluster around the sinusoids, and are required for HSC maintenance. Other cell populations with reported contributions in this niche are the endothelial cells, macrophages, osteoclasts, and other perivascular stromal cells.

types through the whole testis, and STAT inactivation led to loss of both stem cell populations (Kiger et al., 2001; Tulina and Matunis, 2001). The first hint that the situation was a bit more complex came from studies of the Jak/STAT target gene in CySCs, $z f h-1$ (Leatherman and Dinardo, 2008). Zfh-1 is normally restricted to CySCs, and when expression was artificially maintained in cyst cells, differentiation was prevented and excess stem-like cyst cells accumulated through the testes. Interestingly, accompanying these excess CySC-like cells were also ectopic GSCs, even though the germline cells had received no genetic manipulation themselves. Since this phenotype was similar to that observed with ectopic expression of the hub ligand Upd, the authors next activated Jak/STAT signaling cell autonomously in either the cyst lineage or germ lineage cells. They found that constitutive Jak/STAT in the germ lineage had no effect, while constitutive Jak/STAT in the cyst lineage caused ectopic accumulation of both stem cell populations. Thus, CySCs away from the hub are able to support ectopic GSCs, and this was the first reported example of one stem cell population supporting the self-renewal of a second stem cell population in a shared niche (Leatherman and Dinardo, 2008).

Subsequent studies of this niche have attempted to determine whether the CySCs are necessary for GSC self-renewal during normal tissue homeostasis. Since stat and $z f h-1$ are required for CySCs to be maintained as stem cells, these genes were knocked down by RNAi to test whether loss of CySCs also led to GSC loss. Depletion of either gene product in cyst lineage cells caused a significant reduction in the number of CySCs, which in turn led to a significant reduction in the number of GSCs, further supporting the notion that CySCs are required for GSC maintenance (Leatherman and Dinardo, 2010; Issigonis and Matunis, 2012). Another study provided confusingly mixed results. In this study the apoptotic gene grim was transiently activated in cyst lineage cells, and this treatment led to ablation of all CySCs and cyst cells in about $80 \%$ of the testes. After 1 week, half of the testes had lost all germline cells, while the other half continued to maintain germline cells that failed to differentiate (Lim and Fuller, 2012). In summary, while it is clear that CySCs have the capability to support GSC self-renewal, it is still an open question whether CySCs are absolutely required for GSC maintenance in the setting of the normal niche.

What are the signals produced by CySCs that promote GSC maintenance? GSCs are known to require Jak/STAT and BMP signaling for their maintenance (Kiger et al., 2001; Tulina and Matunis, 2001; Shivdasani and Ingham, 2003; Kawase et al., 2004; Schulz et al., 2004). It is now clear that Jak/STAT signaling in 
GSCs does not regulate their self-renewal, but is required for their adherence to hub cells (Leatherman and Dinardo, 2010). BMP signaling remains as the primary self-renewal-promoting pathway for GSCs. The BMP ligands in the testis niche are $g b b$ and $d p p$, and both are reportedly expressed in the hub and CySCs, consistent with the ability of CySCs to promote GSC self-renewal (Shivdasani and Ingham, 2003; Kawase et al., 2004). It is unclear why the GSCs might require BMPs from two cellular sources. It could be that BMP ligands only reach high enough levels for GSC self-renewal when produced from both the hub and CySCs, or there could be a difference in the ligand composition in the hub versus the CySCs (homodimers versus heterodimers, for example). Alternatively, there may be additional self-renewal factors that have not yet been identified, and these could be differentially expressed between the hub and the CySCs.

\section{THE HAIR FOLLICLE NICHE}

Hair follicles are complex structures that cycle through periods of hair growth (anagen), followed by follicle regression (catagen). Between each growth cycle is a period of dormancy called telogen. Numerous distinct stem cell subpopulations have been identified within the hair follicle, with differing abilities to contribute to structures including the hair follicle itself, the interfollicular epidermis, and the sebaceous gland (Goldstein and Horsley, 2012). We will focus here on the stem cells supporting hair formation, called hair follicle stem cells (HFSCs, also called keratinocyte or epithelial stem cells). These stem cells are located in the upper, permanent region of the hair follicle called the bulge, and are identified by their slow-cycling behavior, and by the expression of Keratin-15 and CD34 (Cotsarelis et al., 1990; Lyle et al., 1998; Trempus et al., 2003). A second cell population, Lgr5-positive cells of the secondary hair germ ( $\mathrm{sHG}$ ), reside slightly basal to the bulge during telogen, but are also long-lived stem cells that support hair formation (Jaks et al., 2008; Figure 1B).

During anagen, the dividing hair matrix cells - the descendents of HFSCs - cluster around the dermal papilla and divide to produce cells that differentiate into the main structure of the hair fiber. Interspersed with the matrix cells are melanocytes, which produce melanin granules that are transferred to the matrix cells, thus pigmenting the hair shaft (Slominski et al., 2005). The stem cells supporting the production of new melanocytes each hair follicle cycle are the neural crest-derived melanocyte stem cells (MISCs; note: melanocyte and mesenchymal stem cells (MsSCs) are both commonly abbreviated as "MSCs"; since we discuss both here, we will use different abbreviations). When MlSCs are not maintained, hair graying results (Nishimura et al., 2005). The MlSCs also reside in the bulge and sHG, sharing a niche with the HFSCs (Nishimura et al., 2002). Just as in the Drosophila testis niche, the HFSCs and MISCs must coordinate their mitotic behavior, so that their differentiated cell types accumulate at the same time to accomplish hair pigmentation during anagen.

Several recent reports suggest that MISCs rely on HFSCs for signals that regulate their behavior at multiple stages of the hair follicle cycle. In early anagen, Wnt signaling in HFSCs promotes proliferation and differentiation of stem cells into matrix cells (Van Mater et al., 2003; Lowry et al., 2005). Recent work indicates that
MISCs also respond to Wnt signaling: loss of $\beta$-catenin specifically in MlSCs led to a strong reduction in the number of differentiated melanocytes, and a reduction in the MISC mitotic rate (Rabbani et al., 2011). Thus, both stem cell populations are activated during anagen by Wnt signaling. While the MlSCs do not express Wnt ligands, several Wnts are specifically upregulated in the bulge and sHG HFSCs in early anagen (Rabbani et al., 2011). In addition, wntless, which is required for Wnt ligand secretion, is also strongly expressed in the HFSCs during early anagen (Fu et al., 2009). Thus, while this work could not exclude an additional contribution of Wnt ligands from other sources, it is clear that one source of Wnts are the HFSCs (Rabbani etal., 2011). Thus the HFSCs promote entry of the MlSCs into anagen.

Rabbani et al. also tested the effect of constitutive HFSC Wnt signaling on neighboring MISCs. They found that HFSC $\beta$-catenin stabilization had a strong non-autonomous effect on MlSCs, dramatically increasing their proliferation rate (Rabbani et al., 2011). In these dramatically expanded bulges, the gene encoding the secreted factor endothelin1 was strongly upregulated. Endothelin1 is a known transcriptional target of Wnt signaling in colon cancer cells, and is also a mitogen for melanocytes (Kim et al., 2005; Saldana-Caboverde and Kos, 2010). The authors went on to demonstrate that MlSCs express endothelin receptors, and injection of a pharmacological endothelin inhibitor prevented the MlSC expansion observed with constitutive Wnt in HFSCs, indicating that the MlSC expansion was indeed mediated via HFSC-secreted endothelin (Rabbani et al., 2011). Thus, HFSCs support entry of MlSCs into anagen via expression of both Wnts and Endothelin1.

Another recent report has implicated endothelin2 in coordination of the HFSCs and MlSCs. Chang et al. identified an unusual phenotype - when HFSCs were mutant for the transcription factor $N f i b$, the two stem cell populations lost their coordinated behavior, and MlSCs differentiated into melanocytes during telogen, when they should have remained as quiescent stem cells. The authors found that endothelin2 was overexpressed in Nfib-mutant hair follicles, and that NFIB binds directly to regulatory elements near the endothelin2 gene. Unlike endothelin1, endothelin2 levels were not affected by Wnt signaling. Thus, Nfib expression in HFSCs is required to repress endothelin2 expression, thus promoting quiescence of neighboring MlSCs during telogen (Chang et al., 2013).

MISCs stop dividing and become quiescent in mid-anagen of each hair follicle cycle, and Nishimura et al. have identified TGF $\beta$ as a key factor that promotes their mitotic quiescence at this stage Cultured MISCs responded to TGF $\beta$ by withdrawing from the cell cycle, and loss of the TGF $\beta$ receptor II in MISCs led to progressive hair graying in mice. These mice had ectopically differentiated melanocytes present in the bulge, presumably from a failure to establish quiescence, and thereby maintain a long-term bulge stem cell population (Nishimura et al., 2010). While the TGF $\beta$ ligand was detected in the niche, the source of the ligand was initially unclear. A more recent report has clarified that the HFSCs are the source of this ligand, as production of TGF $\beta$ ligand requires HFSC expression of collagen XVII (Tanimura et al., 2011). Thus, HFSCs also regulate entry of MlSCs into quiescence in mid-anagen via expression of TGF $\beta$. 


\section{THE BONE MARROW NICHE}

Hematopoietic stem cells (HSCs) are some of the best studied of all adult stem cells, but their in vivo niche in the bone marrow is exceedingly complex. Initial reports implicated the region next to the bone surface, called the endosteum, as the niche (Nilsson et al., 2001; Calvi et al., 2003; Zhang et al., 2003; Figure 1C). Transplanted HSCs homed to the endosteum, and osteoblast lineage expansion, either via parathormone treatment or BMP receptor $1 \mathrm{~A}$ inhibition, caused excess HSCs to accumulate. However, subsequent manipulations of osteoblasts produced mixed results some reports found that osteoblast loss led to HSC loss (Visnjic et al., 2004), while other reports found no effect, or even loss of HSCs upon osteoblast expansion (Lymperi et al., 2008; Ma et al., 2009; Schepers et al., 2012). Subsequent reports suggested that osteoblasts per se were not so important, but rather, some population of osteoprogenitor cells may be the critical niche component for HSCs (Chitteti et al., 2010; Nakamura et al., 2010; Calvi et al., 2012).

In 2005, Kiel et al. (2005) identified a new method to distinguish HSCs from early non-stem progenitor cells using the SLAM family of cell surface receptors. Surprisingly, they reported that many HSCs localize next to the endothelial cells that make up the blood vessels, or sinusoids, in the bone marrow, and only a few HSCs are found on the endosteum. Thus, the authors proposed the existence of two distinct niches for HSCs. It remains an open question whether the endosteal and vascular niches both carry out a similar function, or whether they have unique roles to play. For example, some have argued that one niche is where the more primitive, quiescent HSCs reside, while the other niche harbors activated HSCs or early differentiating progenitor cells (Ehninger and Trumpp, 2011; Ding and Morrison, 2013).

The bone marrow is also the home of a second stem cell population, the MsSCs, also known as skeletal or stromal stem cells. These stem cells produce cells which differentiate into bone, cartilage, and fat, and they have been classically defined by their ability to regenerate a hematopoietic environment in an ectopic in vivo location (Tavassoli and Crosby, 1968). MsSCs with this regenerative capacity have recently been molecularly identified as MCAM+, CD146+ cells, and these cells reside next to the sinusoids in the bone marrow (Sacchetti et al., 2007; Figure 1C). Another group identified nestinGFP-positive cells as MsSCs, based on their ability to form clonal self-renewing mesenchymal spheres ("mesenspheres"), and differentiate into mesenchymal lineages in vitro and in vivo (Mendez-Ferrer etal., 2010). NestinGFPpositive cells also reside next to blood vessels, and interestingly, nearly all HSCs were found in the immediate vicinity of a nestinGFP-positive cell (even the HSCs at the endosteum were near a perivascular nestinGFP-positive cell).

Several experiments have provided strong evidence that MsSCs are a key component of the HSC niche. First, nestinGFP-positive MsSCs express high levels of genes required for HSC maintenance, including Cxcl12, SCF, interleukin-7, angiopoietin-1, Vcam1, and osteopontin (Mendez-Ferrer et al., 2010). Ablation of nestinGFP-positive cells resulted in a rapid reduction in the numbers of HSCs in the bone marrow, accompanied by mobilization of HSCs to the spleen. Lethal irradiation of mice depleted for nestinGFP-positive cells showed markedly reduced homing of hematopoietic progenitors to the bone marrow, suggesting that their niche is compromised. HSC mobilization is known to be under circadian control via signals from the sympathetic nervous system, and nestinGFP-positive cells are in fact innervated with sympathetic neurons from the blood vessels (Mendez-Ferrer et al., 2008, 2010). HSC mobilization can be induced by granulocyte colony-stimulating factor (G-CSF), which leads to down regulation of HSC self-renewal factors (Semerad et al., 2005; Katayama et al., 2006). Mendez-Ferrer et al. found that G-CSF caused downregulation of HSC self-renewal factors specifically in nestinGFPpositive cells, as well as a decrease in the nestinGFP-positive cell proliferation levels (Mendez-Ferrer et al., 2010). Parathormone treatment, which was previously shown to expand HSC numbers (presumably by increasing the size of the niche), led to a doubling in the number of nestinGFP-positive cells, while activation of parathormone signaling in only differentiated osteoblasts had no effect on HSC numbers (Mendez-Ferrer et al., 2010; Calvi et al., 2012). Finally, cotransplantation of MsSCs along with HSCs during transplantation greatly improved HSC engraftment and self-renewal (Masuda et al., 2009; Ahn et al., 2010). All these data support the notion that MsSCs help support the self-renewal of HSCs.

Significant questions remain about the exact identity of the perivascular MsSCs that support HSC self-renewal. Confusingly, it seems that nestinGFP-positive cells do not actually express the nestin gene or nestin-CRE (Ding et al., 2012). Ding et al. identified leptin receptor-expressing perivascular cells as being necessary sources of the HSC self-renewal factors SCF and CXCL12 (Ding etal., 2012; Ding and Morrison, 2013). While the described nestinGFP-positive MsSCs and the leptin receptor-positive cell populations likely have significant overlap, it is unclear whether they represent identical cell populations. Ding et al. also found that tissue-specific knock-out of $S c f$ or $C x c l 12$ from endothelial cells caused HSC depletion, suggesting that this cell population is also required for HSC self-renewal (Ding et al., 2012). In addition to the above-mentioned niche components, macrophages and osteoclasts have also been implicated in HSC renewal (Kollet et al., 2006; Winkler et al., 2010; Chow et al., 2011; Mansour et al., 2012; Figure 1C). Thus, MsSCs are one of several niche components required for HSC self-renewal.

In summary, three niches have now been found to use stem cells to support other stem cells, representing a new paradigm in niche biology. In two of the niches, the differentiating progeny function together, necessitating coordination of the stem cell populations. In mammals, MsSCs are found in many tissues, not just the bone marrow, and these cells could be involved in maintaining other stem cell populations in addition to HSCs. MsSCs are frequently used in therapeutic stem cell treatments, due to their safety and the ease with which they can be obtained (Lee, 2012). Future work will determine whether their therapeutic effects may be mediated primarily via endogenous stem cell populations, or whether they act on all cells equally. MsSCs also appear to support another type of undifferentiated cell - cancer cells. MsSCs are recruited to, and envelope tumors, and have been implicated as a niche for breast and leukemia cancer stem cells (Liu et al., 2011; Doan and Chute, 2012; Droujinine et al., 2013). In the future, as we learn more about the normal signaling between stem cell populations in niches, our 
ability to manipulate these cells in vivo will improve, increasing our capacity to understand and treat disease states.

\section{REFERENCES}

Ahn, J. Y., Park, G., Shim, J. S., Lee, J. W., and Oh, I. H. (2010). Intramarrow injection of beta-catenin-activated, but not naive mesenchymal stromal cells stimulates self-renewal of hematopoietic stem cells in bone marrow. Exp. Mol. Med. 42, 122-131. doi: 10.3858/emm.2010.42.2.014

Calvi, L. M., Adams, G. B., Weibrecht, K. W., Weber, J. M., Olson, D. P., Knight, M. C., et al. (2003). Osteoblastic cells regulate the haematopoietic stem cell niche. Nature 425, 841-846. doi: 10.1038/nature02040

Calvi, L. M., Bromberg, O., Rhee, Y., Weber, J. M., Smith, J. N., Basil, M. J., et al. (2012). Osteoblastic expansion induced by parathyroid hormone receptor signaling in murine osteocytes is not sufficient to increase hematopoietic stem cells. Blood 119, 2489-2499. doi: 10.1182/blood-2011-06-360933

Caplan, A. I., and Dennis, J. E. (2006). Mesenchymal stem cells as trophic mediators. J. Cell. Biochem. 98, 1076-1084. doi: 10.1002/jcb.20886

Chang, C. Y., Pasolli, H. A., Giannopoulou, E. G., Guasch, G., Gronostajski, R. M., Elemento, O., et al. (2013). NFIB is a governor of epithelial-melanocyte stem cell behaviour in a shared niche. Nature 495, 98-102. doi: 10.1038/nature11847

Chitteti, B. R., Cheng, Y. H., Streicher, D. A., Rodriguez-Rodriguez, S., Carlesso, N., Srour, E. F., et al. (2010). Osteoblast lineage cells expressing high levels of Runx2 enhance hematopoietic progenitor cell proliferation and function. J. Cell. Biochem. 111, 284-294. doi: 10.1002/jcb.22694

Chow, A., Lucas, D., Hidalgo, A., Mendez-Ferrer, S., Hashimoto, D., Scheiermann, C., et al. (2011). Bone marrow CD169+ macrophages promote the retention of hematopoietic stem and progenitor cells in the mesenchymal stem cell niche. $J$. Exp. Med. 208, 261-271. doi: 10.1084/jem.20101688

Cotsarelis, G., Sun, T. T., and Lavker, R. M. (1990). Label-retaining cells reside in the bulge area of pilosebaceous unit: implications for follicular stem cells, hair cycle, and skin carcinogenesis. Cell 61, 1329-1337. doi: 10.1016/0092-8674(90)90696-C

Dezawa, M., Ishikawa, H., Itokazu, Y., Yoshihara, T., Hoshino, M., Takeda, S., et al. (2005). Bone marrow stromal cells generate muscle cells and repair muscle degeneration. Science 309, 314-317. doi: 10.1126/science.1110364

Ding, L., and Morrison, S. J. (2013). Haematopoietic stem cells and early lymphoid progenitors occupy distinct bone marrow niches. Nature 495, 231-235. doi: $10.1038 /$ nature 11885

Ding, L., Saunders, T. L., Enikolopov, G., and Morrison, S. J. (2012). Endothelial and perivascular cells maintain haematopoietic stem cells. Nature 481, 457-462. doi: 10.1038/nature 10783

Doan, P. L., and Chute, J. P. (2012). The vascular niche: home for normal and malignant hematopoietic stem cells. Leukemia 26, 54-62. doi: 10.1038/leu.2011.236

Droujinine, I. A., Eckert, M. A., and Zhao, W. (2013). To grab the stroma by the horns: from biology to cancer therapy with mesenchymal stem cells. Oncotarget 4, 651-664.

Ehninger, A., and Trumpp, A. (2011). The bone marrow stem cell niche grows up: mesenchymal stem cells and macrophages move in. J. Exp. Med. 208, 421-428. doi: $10.1084 /$ jem.20110132

Fu, J., Jiang, M., Mirando, A. J., Yu, H. M., and Hsu, W. (2009). Reciprocal regulation of Wnt and Gpr177/mouse Wntless is required for embryonic axis formation. Proc. Natl. Acad. Sci. U.S.A. 106, 18598-18603. doi: 10.1073/pnas.0904894106

Gnecchi, M., Zhang, Z., Ni, A., and Dzau, V. J. (2008). Paracrine mechanisms in adult stem cell signaling and therapy. Circ. Res. 103, 1204-1219. doi: 10.1161/CIRCRESAHA.108.176826

Goldstein, J., and Horsley, V. (2012). Home sweet home: skin stem cell niches. Cell. Mol. Life Sci. 69, 2573-2582. doi: 10.1007/s00018-012-0943-3

Hardy, R. W., Tokuyasu, K. T., Lindsley, D. L., and Garavito, M. (1979). The germinal proliferation center in the testis of Drosophila melanogaster. J. Ultrastruct. Res. 69, 180-190. doi: 10.1016/S0022-5320(79)90108-4

Issigonis, M., and Matunis, E. (2012). The Drosophila BCL6 homolog Ken and Barbie promotes somatic stem cell self-renewal in the testis niche. Dev. Biol. 368, 181-192. doi: 10.1016/j.ydbio.2012.04.034

Jaks, V., Barker, N., Kasper, M., Van Es, J. H., Snippert, H. J., Clevers, H., et al. (2008). Lgr5 marks cycling, yet long-lived, hair follicle stem cells. Nat. Genet. 40, 1291-1299. doi: 10.1038/ng.239

Katayama, Y., Battista, M., Kao, W. M., Hidalgo, A., Peired, A. J., Thomas, S. A., et al. (2006). Signals from the sympathetic nervous system regulate hematopoietic stem cell egress from bone marrow. Cell 124, 407-421. doi: 10.1016/j.cell.2005.10.041
Kawase, E., Wong, M. D., Ding, B. C., and Xie, T. (2004). Gbb/Bmp signaling is essential for maintaining germline stem cells and for repressing bam transcription in the Drosophila testis. Development 131, 1365-1375. doi: 10.1242/dev.01025

Kiel, M. J., Yilmaz, O. H., Iwashita, T., Terhorst, C., and Morrison, S. J. (2005). SLAM family receptors distinguish hematopoietic stem and progenitor cells and reveal endothelial niches for stem cells. Cell 121, 1109-1121. doi: 10.1016/j.cell.2005.05.026

Kiger, A. A., Jones, D. L., Schulz, C., Rogers, M. B., and Fuller, M. T. (2001). Stem cell self-renewal specified by JAK-STAT activation in response to a support cell cue. Science 294, 2542-2545. doi: 10.1126/science.1066707

Kim, T. H., Xiong, H., Zhang, Z., and Ren, B. (2005). beta-Catenin activates the growth factor endothelin-1 in colon cancer cells. Oncogene 24, 597-604. doi: 10.1038/sj.onc.1208237

Kollet, O., Dar, A., Shivtiel, S., Kalinkovich, A., Lapid, K., Sztainberg, Y., et al. (2006). Osteoclasts degrade endosteal components and promote mobilization of hematopoietic progenitor cells. Nat. Med. 12, 657-664. doi: 10.1038/nm1417

Leatherman, J. L., and Dinardo, S. (2008). Zfh-1 controls somatic stem cell selfrenewal in the Drosophila testis and nonautonomously influences germline stem cell self-renewal. Cell Stem Cell 3, 44-54. doi: 10.1016/j.stem.2008.05.001

Leatherman, J. L., and Dinardo, S. (2010). Germline self-renewal requires cyst stem cells and stat regulates niche adhesion in Drosophila testes. Nat. Cell Biol. 12, 806-811. doi: $10.1038 /$ ncb2086

Lee, T. (2012). Stem cell therapy independent of stemness. World J. Stem Cells 4, 120-124. doi: 10.4252/wjsc.v4.i12.120

Lim, J. G., and Fuller, M. T. (2012). Somatic cell lineage is required for differentiation and not maintenance of germline stem cells in Drosophila testes. Proc. Natl. Acad. Sci. U.S.A. 109, 18477-18481. doi: 10.1073/pnas.1215516109

Liu, S., Ginestier, C., Ou, S. J., Clouthier, S. G., Patel, S. H., Monville, F., et al. (2011). Breast cancer stem cells are regulated by mesenchymal stem cells through cytokine networks. Cancer Res. 71, 614-624. doi: 10.1158/0008-5472.CAN-10-0538

Lowry, W. E., Blanpain, C., Nowak, J. A., Guasch, G., Lewis, L., and Fuchs, E. (2005). Defining the impact of beta-catenin/Tcf transactivation on epithelial stem cells. Genes Dev. 19, 1596-1611. doi: 10.1101/gad.1324905

Lyle, S., Christofidou-Solomidou, M., Liu, Y., Elder, D. E., Albelda, S., and Cotsarelis, G. (1998). The C8/144B monoclonal antibody recognizes cytokeratin 15 and defines the location of human hair follicle stem cells. J. Cell Sci. 111(Pt 21), 3179-3188.

Lymperi, S., Horwood, N., Marley, S., Gordon, M. Y., Cope, A. P., and Dazzi, F. (2008). Strontium can increase some osteoblasts without increasing hematopoietic stem cells. Blood 111, 1173-1181. doi: 10.1182/blood-2007-03-082800

Ma, Y. D., Park, C., Zhao, H., Oduro, K. A. Jr., Tu, X., Long, F., et al. (2009). Defects in osteoblast function but no changes in long-term repopulating potential of hematopoietic stem cells in a mouse chronic inflammatory arthritis model. Blood 114, 4402-4410. doi: 10.1182/blood-2008-12-196311

Mansour, A., Abou-Ezzi, G., Sitnicka, E., Jacobsen, S. E., Wakkach, A., and Blin-Wakkach, C. (2012). Osteoclasts promote the formation of hematopoietic stem cell niches in the bone marrow. J. Exp. Med. 209, 537-549. doi: 10.1084/jem.20110994

Masuda, S., Ageyama, N., Shibata, H., Obara, Y., Ikeda, T., Takeuchi, K., et al. (2009). Cotransplantation with MSCs improves engraftment of HSCs after autologous intra-bone marrow transplantation in nonhuman primates. Exp. Hematol. 37, 1250-1257.e1. doi: 10.1016/j.exphem.2009.07.008

McDonald, J. W., Liu, X. Z., Qu, Y., Liu, S., Mickey, S. K., Turetsky, D., et al. (1999). Transplanted embryonic stem cells survive, differentiate and promote recovery in injured rat spinal cord. Nat. Med. 5, 1410-1412. doi: 10.1038/70986

Mendez-Ferrer, S., Lucas, D., Battista, M., and Frenette, P. S. (2008). Haematopoietic stem cell release is regulated by circadian oscillations. Nature 452, 442-447. doi: 10.1038 /nature06685

Mendez-Ferrer, S., Michurina, T. V., Ferraro, F., Mazloom, A. R., MacArthur, B. D., Lira, S. A., et al. (2010). Mesenchymal and haematopoietic stem cells form a unique bone marrow niche. Nature 466, 829-834. doi: 10.1038/nature09262

Nakamura, Y., Arai, F., Iwasaki, H., Hosokawa, K., Kobayashi, I., Gomei, Y., et al. (2010). Isolation and characterization of endosteal niche cell populations that regulate hematopoietic stem cells. Blood 116, 1422-1432. doi: 10.1182/blood2009-08-239194

Nilsson, S. K., Johnston, H. M., and Coverdale, J. A. (2001). Spatial localization of transplanted hemopoietic stem cells: inferences for the localization of stem cell niches. Blood 97, 2293-2299. doi: 10.1182/blood.V97.8.2293 
Nishimura, E. K., Granter, S. R., and Fisher, D. E. (2005). Mechanisms of hair graying: incomplete melanocyte stem cell maintenance in the niche. Science 307, 720-724. doi: 10.1126/science. 1099593

Nishimura, E. K., Jordan, S. A., Oshima, H., Yoshida, H., Osawa, M., Moriyama, M., et al. (2002). Dominant role of the niche in melanocyte stem-cell fate determination. Nature 416, 854-860. doi: 10.1038/416854a

Nishimura, E. K., Suzuki, M., Igras, V., Du, J., Lonning, S., Miyachi, Y., et al. (2010). Key roles for transforming growth factor beta in melanocyte stem cell maintenance. Cell Stem Cell 6, 130-140. doi: 10.1016/j.stem.2009.12.010

Orlic, D., Kajstura, J., Chimenti, S., Jakoniuk, I., Anderson, S. M., Li, B., et al. (2001). Bone marrow cells regenerate infarcted myocardium. Nature 410, 701-705. doi: 10.1038/35070587

Pelacho, B., and Prosper, F. (2008). Stem cells and cardiac disease: where are we going? Curr. Stem Cell Res. Ther. 3, 265-276. doi: 10.2174/157488808786734015

Rabbani, P., Takeo, M., Chou, W., Myung, P., Bosenberg, M., Chin, L., et al. (2011). Coordinated activation of Wnt in epithelial and melanocyte stem cells initiates pigmented hair regeneration. Cell 145, 941-955. doi: 10.1016/j.cell.2011.05.004

Sacchetti, B., Funari, A., Michienzi, S., Di Cesare, S., Piersanti, S., Saggio I., et al. (2007). Self-renewing osteoprogenitors in bone marrow sinusoids can organize a hematopoietic microenvironment. Cell 131, 324-336. doi 10.1016/j.cell.2007.08.025

Saldana-Caboverde, A., and Kos, L. (2010). Roles of endothelin signaling in melanocyte development and melanoma. Pigment Cell Melanoma Res. 23 160-170. doi: 10.1111/j.1755-148X.2010.00678.x

Schepers, K., Hsiao, E. C., Garg, T., Scott, M. J., and Passegue, E. (2012). Activated Gs signaling in osteoblastic cells alters the hematopoietic stem cell niche in mice. Blood 120, 3425-3435. doi: 10.1182/blood-2011-11-395418

Schulz, C., Kiger, A. A., Tazuke, S. I., Yamashita, Y. M., Pantalena-Filho, L. C., Jones, D. L., et al. (2004). A misexpression screen reveals effects of bag-of-marbles and TGFbeta class signaling on the Drosophila male germ-line stem cell lineage. Genetics 167, 707-723. doi: 10.1534/genetics.103.023184

Semerad, C. L., Christopher, M. J., Liu, F., Short, B., Simmons, P. J., Winkler, I., et al. (2005). G-CSF potently inhibits osteoblast activity and CXCL12 mRNA expression in the bone marrow. Blood 106, 3020-3027. doi: 10.1182/blood-200401-0272

Shivdasani, A. A., and Ingham, P. W. (2003). Regulation of stem cell maintenance and transit amplifying cell proliferation by tgf-beta signaling in Drosophila spermatogenesis. Curr. Biol. 13, 2065-2072. doi: 10.1016/j.cub.2003. 10.063

Slominski, A., Wortsman, J., Plonka, P. M., Schallreuter, K. U., Paus, R., and Tobin, D. J. (2005). Hair follicle pigmentation. J. Invest. Dermatol. 124, 13-21. doi: 10.1111/j.0022-202X.2004.23528.x

Tanimura, S., Tadokoro, Y., Inomata, K., Binh, N. T., Nishie, W., Yamazaki, S., et al. (2011). Hair follicle stem cells provide a functional niche for melanocyte stem cells. Cell Stem Cell 8, 177-187. doi: 10.1016/j.stem.2010.11.029

Tavassoli, M., and Crosby, W. H. (1968). Transplantation of marrow to extramedullary sites. Science 161, 54-56. doi: 10.1126/science.161.3836.54
Trempus, C. S., Morris, R. J., Bortner, C. D., Cotsarelis, G., Faircloth, R. S., Reece, J. M., et al. (2003). Enrichment for living murine keratinocytes from the hair follicle bulge with the cell surface marker CD34. J. Invest. Dermatol. 120, 501-511. doi: 10.1046/j.1523-1747.2003.12088.x

Tulina, N., and Matunis, E. (2001). Control of stem cell self-renewal in Drosophila spermatogenesis by JAK-STAT signaling. Science 294, 2546-2549. doi: $10.1126 /$ science. 1066700

Uccelli, A., Morando, S., Bonanno, S., Bonanni, I., Leonardi, A., and Mancardi, G. (2011). Mesenchymal stem cells for multiple sclerosis: does neural differentiation really matter? Curr. Stem Cell Res. Ther. 6, 69-72. doi: $10.2174 / 157488811794480744$

Van Mater, D., Kolligs, F. T., Dlugosz, A. A., and Fearon, E. R. (2003). Transient activation of beta-catenin signaling in cutaneous keratinocytes is sufficient to trigger the active growth phase of the hair cycle in mice. Genes Dev. 17, 1219-1224. doi: 10.1101/gad.1076103

Visnjic, D., Kalajzic, Z., Rowe, D. W., Katavic, V., Lorenzo, J., and Aguila, H. L. (2004). Hematopoiesis is severely altered in mice with an induced osteoblast deficiency. Blood 103, 3258-3264. doi: 10.1182/blood-2003-11-4011

Winkler, I. G., Sims, N. A., Pettit, A. R., Barbier, V., Nowlan, B., Helwani, F., et al. (2010). Bone marrow macrophages maintain hematopoietic stem cell (HSC) niches and their depletion mobilizes HSCs. Blood 116, 4815-4828. doi: 10.1182/blood-2009-11-253534

Yamashita, Y. M., Jones, D. L., and Fuller, M. T. (2003). Orientation of asymmetric stem cell division by the APC tumor suppressor and centrosome. Science 301, 1547-1550. doi: 10.1126/science. 1087795

Zandonella, C. (2005). Stem-cell therapies: the first wave. Nature 435, 877-878. doi: $10.1038 / 435877$ a

Zhang, J., Niu, C., Ye, L., Huang, H., He, X., Tong, W. G., et al. (2003). Identification of the haematopoietic stem cell niche and control of the niche size. Nature 425, 836-841. doi: 10.1038/nature02041

Conflict of Interest Statement: The author declares that the research was conducted in the absence of any commercial or financial relationships that could be construed as a potential conflict of interest.

Received: 24 October 2013; accepted: 11 November 2013; published online: 03 December 2013.

Citation: Leatherman J (2013) Stem cells supporting other stem cells. Front. Genet. 4:257. doi: 10.3389/fgene.2013.00257

This article was submitted to Epigenomics and Epigenetics, a section of the journal Frontiers in Genetics.

Copyright (C) 2013 Leatherman. This is an open-access article distributed under the terms of the Creative Commons Attribution License (CC BY). The use, distribution or reproduction in other forums is permitted, provided the original author(s) or licensor are credited and that the original publication in this journal is cited, in accordance with accepted academic practice. No use, distribution or reproduction is permitted which does not comply with these terms. 